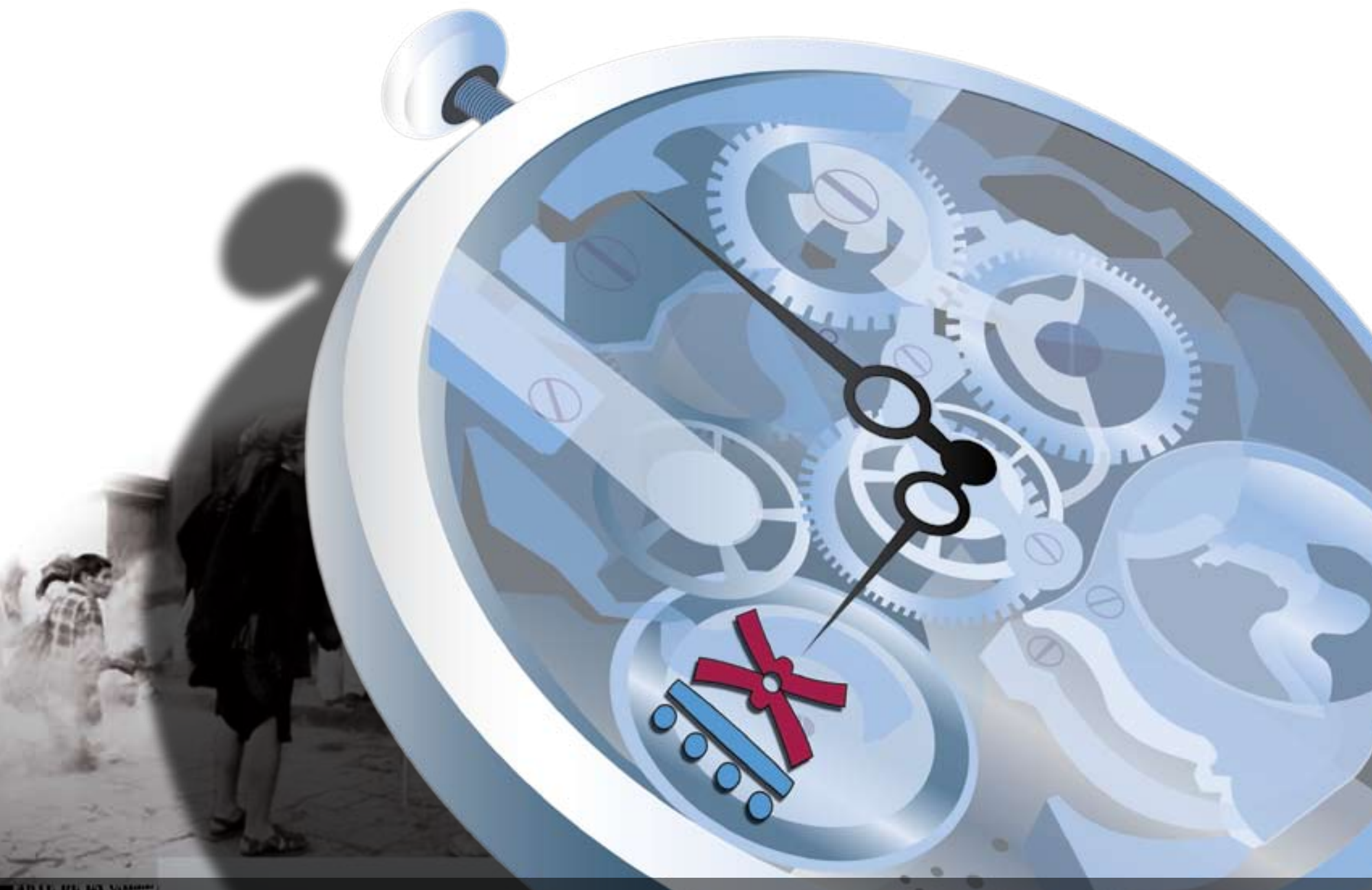

$9^{\circ}$ C O N G R E S O CENTROAMERICANO DE H IS TO R I A

Universidad de Costa Rica

ISSN 1409- 469X

Fecha de recepción: 15 de mayo 2008 Fecha de aceptación: 30 de mayo 2008

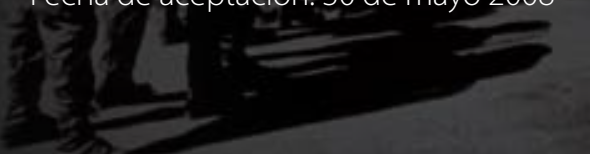

Transformaciones de largo plazo en la agricultura tradicional guanacasteca: redes de conocimiento y cambio técnico en el cantón de Santa Cruz. (1950-1990)

Miembros del Consejo Editorial:

Dr. Ronny Viales, Dr. Juan José Marín

Editores Técnicos:

Allan Fonseca, Andrés Cruz, Gabriela Soto
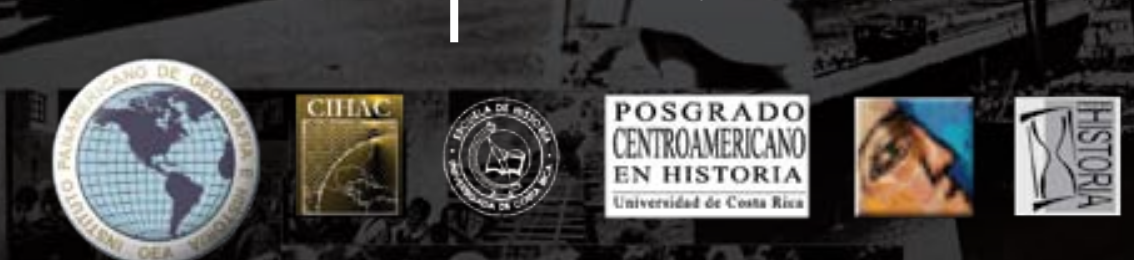
Indexaciones: Repositorio de Revistas UCR, DIALNET, Latindex, REDALYC Directorio y recolector de recursos digitales del Ministerio de Cultura de España, Directory of Open Access Journals. Diálogos Revista Electrónica de Historia ISSN 1409- 469X. Número especial 2008. Dirección web: http://historia.fcs.ucr.ac.cr/dialogos.htm

\section{“Transformaciones de largo plazo en la agricultura tradicional guanacasteca: redes de conocimiento y cambio técnico en el cantón de Santa Cruz. (1950-1990)"}

Br. Yanina Pizarro Méndez

Estudiante de Posgrado de Historia de la UNA

Dirección: Santa Cruz, Guanacaste, Costa Rica

Teléfono: 88101395

Correo electrónico: yanipict@yahoo.es 
La investigación plantea las transformaciones de la agricultura de granos básicos en Santa Cruz, enmarcados en el marco conceptual de los sistemas agrarios, así como los procesos de innovación y los cambios en la agricultura. Además, la investigación se sustenta mediante la transferencia técnica promovida por redes de conocimiento, formales e informales ${ }^{1}$. Para efectos metodológicos, se delimitó una zona de estudio, la cual comprendió las comunidades de Lagunilla, San Pedro, 27 de Abril, Las Delicias y Chircó, conocidas por los altos índices de producción de granos básicos. (Ver Anexo No 1. Mapa de la zona en estudio). Se analizó un periodo estructural, entre 1950 - 1990. Dentro de este lapso, se establecieron dos fases, la primera de 1950-1978, donde se evidencia la adaptación de la agricultura de cambio y por último, entre 1978 y 1990, en la que los agricultores mostraron una dependencia al paquete tecnológico y a la vez se inició la desestructuración del sector, debido a variantes internas y externas.

\section{El cambio técnico en la agricultura de granos básicos en Santa Cruz, un largo proceso de transformación (1950-1978)}

A partir de 1950, se inició en Costa Rica un proceso de modernización de la agricultura de granos básicos, con una amplia influencia del cambio técnico ocurrido en los Estados Unidos. Esta fase se inició desde las décadas de los años veinte y treinta, tras la crisis económica y la Segunda Guerra Mundial, proceso conocido como la Revolución Verde. Este proceso amplió el

1 En el balance conceptual influyeron los trabajos de Dufumier, Marc. Historia agraria para los agrónomos. Revista de Historia. No. 47.Heredia, Costa Rica. Editorial de la Universidad Nacional. Enero-junio, 2003; Piñero, Martín. Transición tecnológica y diferenciación social en la agricultura latinoamericana. San José. Instituto Interamericano de Cooperación para la agricultura. 1986; Samper, Mario. Redes sociales y comunicación entre experimentadores campesinos en Puriscal. Costa Rica. UNA; Inarte, Eduardo. Articulación entre generación y transferencia de tecnológica agropecuaria. Elementos sobre la elaboración sobre un marco de Referencia para la cooperación del IICA en transferencia de Tecnología. San José, Costa Rica. Serie Publicaciones Miscelaneas. 1990; entre otros. 
desarrollo de nuevas variedades vegetales, producto de las modificaciones genéticas, así como fertilizantes, herbicidas y plaguicidas, en un contexto de pleno desarrollo de la industria química. De manera complementaria, se avanzó al uso de herramientas mecánicas y adaptaciones de fuerza automotriz, que se tradujeron en un aumento sustancial de la producción agrícola. ${ }^{2}$

Los países latinoamericanos poseedores de un sistema productivo tradicional, optaron por una modernización, mediante la política de sustitución de importaciones, por lo tanto, se abocaron a la importación de bienes de capital (innovaciones técnicas), en lugar de bienes terminados (principalmente alimentos). En Costa Rica desde 1942 en la administración del Dr. Rafael Ángel Calderón Guardia, se interesó por convenios con otros países, en especial con Estados Unidos, para mejorar el sector agrícola. Sin embargo, hasta 1950 -1960, el nuevo paquete tecnológico y las novedosas técnicas de cultivo, se adaptaron a las regiones tropicales, para generar un alto porcentaje de producción. No obstante, los insumos poseían altos costos, pero el acelerado crecimiento industrial, provocó la paulatina disminución de los precios y condujo a la apertura de mercados de bienes industriales.

Bajo la Fundación de la Segunda República de José Figueres Ferrer (1953), se concretó el proceso de modernización de la agricultura por medio de la Agencia de Ayuda Estadounidense (STICA). Con ello se inició una estrategia de desarrollo e integración de las zonas rurales, donde se incorporó a los pequeños, medianos y grandes productores. El plan reposaba en los procesos de industrialización y eficiencia productiva para el abastecimiento del mercado nacional. Además, bajo el Plan de Desarrollo Agropecuario, se estímulo la producción del cantón. ${ }^{3}$ Lo 2 Sfez, Paul. Entre la tradición y el cambio: Evolución Tecnológica de la Caficultora Costarricense. San José. SEE S.A. 2000, p, 60.

3 El Agrario Nacional, 7 de octubre de 1950, p, 7. 
que refleja, que la modernización productiva de Santa Cruz estuvo condicionada por el impulso internacional, nacional y regional. Además, el cantón presentaba condiciones favorables para esta modernización, tales como: una tradición productiva en granos básicos, clima, topografía, suelo, entre otros aspectos. El plan del Estado Benefactor se concretó mediante la creación de instituciones específicas, que cumplían con la función de dirigir y administrar la política del agro, que seguiría funcionando en las posteriores administraciones a Figueres Ferrer.

El conjunto de las instituciones estaba integrado por el Servicio Técnico Interamericano de Cooperación Agrícola y el Consejo Nacional de Productores, ${ }^{4}$ con el fin de estimular la producción agrícola y abastecimiento de granos básicos (arroz y maíz). Además, el Ministerio de Agricultura y Ganadería (MAG), se fortaleció en la segunda mitad del siglo. Estas aperturas suscitaron cambios en los agricultores, primero en la mentalidad capitalista de venta a gran escala de productos, que remplazaba el autoconsumo; pero sobre todo el cambio de las viejas técnicas de producción, por la utilización de equipo moderno.

Las innovaciones técnicas se concretaron por medio de cuatro puntos importantes: 1) la tecnología biológica para mejorar la variedad de las especies, desarrollando híbridos con mejor capacidad de producción y el control de plagas y enfermedades; 2) innovación química en forma de agroquímicos para aumentar la fertilidad del suelo, combatir plagas y malezas; 3) innovaciones agronómicas referidas al cambio en el manejo de los cultivos y variaciones en la cantidad de producción 4) invenciones referidas al uso de maquinarias para realizar diferentes tareas agrícolas. Estos aspectos fueron incorporándose y mejorando paulatinamente, en miras a $4 \quad$ El primero creado en 1949 y el CNP en 1956, aunque el origen de este último se remonta a 1943 cuando se creo la Sección de Fometo a la Producción agrícola, ligada a las juntas rurales. 
conseguir una agricultura totalmente tecnificada.

La apertura del STICA y el CNP en la década de1960 en Santa Cruz, impulsó la modernización por medio de la preparación de la tierra, la siembra y la distribución de semillas. En estos primeros años la atención estatal se distribuía entres los pequeños, medianos y grandes productores. Pero el impacto fue diferenciado entre los productores, ya que los grandes, lideraron la introducción de cambios técnicos, principalmente en el arroz, mientras que los pequeños y medianos productores con el maíz y en menor medida con el arroz, se enrumbaron en un lento proceso de modernización. En este punto la tradición productiva, la solvencia económica, la insuficiencia vial y las simples estrategias de extensión en las dos primeras décadas, fueron las limitantes para alcanzar el cambio técnico total. ${ }^{5}$ Sin embargo, algunos medianos productores al igual que los grandes valoraban la posibilidad de incorporarse al mercado nacional, gracias a la divulgación de los beneficios en la producción de granos básicos, brindada por los entes estatales. Aunque con la adquisición de préstamos, se sentían obligados a cultivar con todas las recomendaciones de los extensionistas, por miedo a perder la cosecha y consecuentemente las tierras por las hipotecas. ${ }^{6}$

En la década del sesenta, el CNP incorporó uno de los aspectos primordiales para el cambio: el abastecimiento de semillas. Las nuevas semillas era importantes debido a que: 1) estas llevan las características genéticas; 2) permitían la renovación constante del ciclo agrícola y por ende, de la producción y del consumo; 3) era necesaria por encima de los fertilizantes y otros insumos; 4) era un insumo del cual el campesino se puede apropiar para el proceso de producción. Además,

5 En el caso santacruceño se limitaba a dotar de semillas a los productores, dependiendo del área disponible.

6 Entrevista con José Maria Gutiérrez. Las Delicias de 27 de Abril, (Santa Cruz), 1-102007. 
los suelos en su mayoría necesitaban de un uso limitado de fertilizantes, ya que era reciente el reemplazo de los bosques por parcelas agropecuarias. ${ }^{7}$ Del mismo modo, esta oficina era la responsable de estimular la producción agrícola para el mercadeo interno.

Los agricultores utilizaron tradicionalmente variedades criollas, en maíz como el Maiceno y arroz Chino, entre otros. La introducción de variedades mejoradas en semillas, provocó la desconfianza de los pequeños y medianos agricultores, ya que implicaba modificaciones importantes en la forma de cultivo y los insumos de producción. La Estación Experimental Enrique Núñez en Cañas, ayudó a la introducción de estas nuevas variedades de semillas, ya que reducían de manera considerable el tiempo de cosecha (de cuatro meses, se pasó a tres meses) y reducía la capacidad de volcamiento (las plantas al ser de porte bajo no se quebraban con tanta facilidad). Asimismo, la empresa privada influyó en la investigación de nuevas variedades de semillas, tal fue el caso de la Arrocera La Gilda ubicada en San Pedro de Santa Cruz, la cual tenía una amplia influencia de investigaciones colombianas y costarricenses. ${ }^{8}$

Lo anterior demuestra que desde temprano los roces y diferencias entre los distintos grupos involucrados en al cambio técnico, se tornaron alrededor de las semillas. En este aspecto, influyeron varios puntos: los insuficientes medios económicos, el nivel educacional, el apego a la tradición, la explotación de tipo extensivo, la inexistente rotación de cultivos, el escaso uso de fuerza motriz, fertilizantes, pesticidas, etc. Por lo tanto, la modernización agrícola influyó en

7 Edelman, Marc. Campesinos contra la globalización, movimientos sociales rurales en Costa Rica. San José. 2005. pp, 101-102.

8 Las variedades que ellos vendía fueron: IR-228 (1971), CICA-4 (1971), CICA-7(1976), CICA -8 (1978), CICA-9 (1979), METICA-1 (1980), Oryzica-1 (1982). Otras muy comunes fueron: CR 5272, CR 1113, 4457, Arroz 50, CR 1821, etc. 
mayor medida en las grandes fincas, que tenían mucha más apertura a los cambios, que generaron mayor rentabilidad en la producción. ${ }^{9}$

Fue hasta finales de 1960 y los principios del la década de 1970, que los pequeños y medianos productores aceptaron otro aspecto como mayor solides del cambio, los fertilizantes, insecticidas y plaguicidas. Esto debido al desgaste paulatino del suelo por la intensificación de los cultivos, las quemas repetitivas para eliminar malezas, la tala de bosque y la concentración de tierra para el sector agropecuario. Por ende, no había más espacios para cultivar. Además, ante la presencia de sequías, los cultivos no se limpiaban de manera natural por las lluvias, por lo que se intensificaron las plagas, hongos y bacteria, a los que había que atacar.

La amplia colaboración del STICA, (mediante la donación de insumos provenientes de los Estados Unidos), la fuerte introducción de fertilizantes por parte de FERTICA desde 1962 y la apertura de oficina cantonal del MAG en Santa Cruz (1970), lograron transferir, mediante la extensión y otros mecanismos de difusión, las bondades de las sustancias agroquímicas a los agricultores. Rápidamente, la fertilización nitrogenada y por abonos se tradujo en cosechas abundantes y crecimiento vigoroso de las plantas. Además se recomendaban herbicidas ${ }^{10}$ para el control de malezas, insectos y los problemas asociados a los hongos, bacterias y virus. ${ }^{11}$ No obstante, para combatir las amenazas animales, se recurría a mecanismos tradicionales, como las carabinas o el envenenamiento.

9 Ministerio de Agricultura y Ganadería. Programa Agropecuario, 1965-1968, San José, Oficina de Planificación Nacional. 1965, pp, 8-9.

10 Como Gramoxone, Clordano y el Gasaprim

11 Alfaro, Javier. Maíz, San José, Departamento agrotécnico del maíz, CNP. 1981. p, 1217. 
La incorporación de maquinaria pesada en Santa Cruz fue muy variada, ya que los grandes productores las integraron entre 1960-1970. Lo anterior, debido a sus condiciones económicas favorables de las fincas arroceras, donde se reemplazaba el elemento humano y el capital se invertía en la fuerza mecánica, tal como arados o rastras, capulínes, sembradoras y cosechadoras. Además, en algunas fincas se utilizaron avionetas para la aplicación de herbicidas e insecticidas. Por lo tanto, la incorporación de las maquinas fue sinónimo de una actividad empresarial, donde los factores de la producción estaban debidamente equilibrados, haciendo de ella una actividad lucrativa y dando paso a una producción industrial, en contraste con el maíz de los medianos y pequeños agricultores, que empleaba menos maquinaria.

Según el Censo Agropecuario de 1973 la mayoría de la maquinaria eran tractores y raspas, porque una de las dificultades era preparar la tierra, comparada con las labores de siembra y de cosecha. (Ver Cuadro No 1) Otros equipos importantes fueron las bombas de espalda, que se podían encontrar en el mercado local o bien mediante préstamos de equipos del MAG. Las maquinarias en general en la década del setenta, se habían convertido en todo un negocio, ya que los grandes productores las alquilaban a los medianos o algunos de estos últimos lograban obtener crédito para la compra de este tipo de equipo, pero según los datos numéricos, aún la cifra era reducida comparado al número de fincas.

El manejo de los cultivos, evolucionó de la tradición al cambio técnico. En los sistemas de cultivos tradicionales los agricultores producían mediante una baja inversión y consecuentemente, con un bajo riesgo. Bajo el nuevo sistema de producción, se tendió a intensificar las innovaciones 
productivas de los granos básicos, ya que iban acompañadas de mejores técnicas de cultivos, reducción de distancias entre cada siembro y el reemplazo de variedades de porte alto por las de baja altura. En general, se convirtieron y mejoraron los recursos disponibles de los productores, para una mayor producción. Tal es el caso del maíz, que pasó a producir de dos a tres mazorcas por planta, logrando un mayor rendimiento por hectárea. Este proceso se intensificó en 1970, mediante pruebas de cultivo en parcelas demostrativas y para finales de la década se tomaron con mayor rigurosidad las recomendaciones de las instituciones estatales. Además, en esta década entraron en funcionamiento otras instituciones para la labor investigativa, como la Finca Experimental de la UCR en Santa Cruz y la apertura del Instituto de Desarrollo Agrario (IDA) para la distribución y titulación de las tierras.

Evidentemente, el cambio en la intervención estatal, llegó a influir en casi todos los aspectos de la vida rural. También es notable, que las administraciones posteriores a Figueres Ferrer, mantuvieron por algunos años más, estos proyectos del Estado Benefactor. El impacto en la producción era importante, sólo el cultivo de maíz representaba en el distrito de 27 de Abril, 1 734 ha, una producción superior a los $1500 \mathrm{~kg}$, para una productividad de 871 kg/ha. Aunado a la 639 ha de arroz, con un producción mayor a los $500 \mathrm{~kg}$ y al menos 371 fincas en plena producción ${ }^{12}$ Por lo tanto, se llegó a convertir en el poblado más productivo del cantón (en el censo no se obtuvo más información para los otros poblados), ya que Santa Cruz llegó a tener una producción de arroz de 2573 kg y de maíz 2817 kg, colocándose como el tercer cantón más productivo en Guanacaste.

12 Dirección General de Estadística y Censo. Censo Agropecuario 1973. San José. Ministerio de Economía., Industria y Comercio. 1974. p, 51. 
Esta participación por parte del Estado, se daba en un contexto de crisis mundial, de la que Costa Rica no pudo escapar. Desde 1972 se presentó un incremento significativo en los precios de los fertilizantes e insumos químicos derivados del petróleo, que a largo plazo se tornarían en una problemática creciente en el sector agrícola. A pesar de esto, la política proteccionista del Estado, solventó la crisis mediante asistencia técnica, crédito, seguro de cosechas, comercialización e incentivos, dada la importancia de algunos de estos productos en la canasta básica costarricense. Sin embargo, el crecimiento de la producción disminuyó paulatinamente hasta 1978 (según los informes de extensión del MAG), cuando se evidenció una fase de recesión, debido a factores desfavorables y a la sobre dependencia a las políticas de apoyo estatal departe de los agricultores. Además, que para estos años el modelo benefactor presentaba signos de agotamiento, ya que el desarrollo había estado ligado a préstamos y ayudas a nivel internacional. No obstante, según manifestaban algunos agricultores, en la Administración Oduber (1974-1978) se dio la última oportunidad para producir significativamente (en especial sí se compara con las administraciones posteriores).

\section{Entre la modernización y la desestructuración de la agricultura de granos básicos en Santa Cruz (1978-1990)}

Entre 1978y 1990, se mostraron limitaciones internas y externas para el desarrollo de la agricultura de cambio. Bajo el liderazgo de Rodrigo Carazo (1978- 1982), el Estado puso en marcha el Plan Nacional de Desarrollo Agropecuario, en coordinación con el Consejo Agropecuario Nacional (CAN) y el Instituto Interamericano de Ciencias Agrícolas (IICA), para incrementar la producción agrícola destinada para el mercado interno y mantener cierto nivel de ingresos a los agricultores, bajo nuevas formas de organización como los Clubes 4-S. El gobernante logró 
articular aspectos proteccionistas para solventar la crisis, lo cual obedecía a un plan prioritario del gobierno ante la disminución inminente en la producción agrícola, tras el incremento de los insumos de la producción.

La sociedad rural necesitaba una modernización de los servicios básicos y de los recursos públicos, para evolucionar a nuevas innovaciones y técnicas del cultivo, ante cambios climáticos (en la década del setenta se presentaron periodos de sequías) y problemas de otro tipo. No obstante, en la administración Carazo se anuló la posibilidad de préstamos a entidades bancarias mundiales, dejando desprotegidos a los pequeños y medianos agricultores. Esto significó la destrucción paulatina de la producción de granos básicos en las zonas rurales, ya que los insumos agrícolas dejaron de ser gratuitos e inalcanzables para la mayoría de los agricultores o bien estos no podían aplicar las dosis adecuadas de agroquímicos a los cultivos.

El Programa de Clubes 4-S como nueva medida, estaba financiado con un préstamo del BIRF, que buscaba una adaptación a la crisis mediante la diversificación agrícola, por medio de huertas caseras y escolares de los socios de estos clubes. Sin embargo, el componente de diversificación, en el largo plazo no fue funcional para los productores. La ayuda tuvo un componente de control social, ya que la dotación de créditos se originó por la necesidad de impedir la aparición de grupos insurgentes en una Centroamérica inestable y minimizar el éxodo a la ciudad en medio de la crisis económica. En 1979 se puso en funcionamiento el Programa de Asignaciones Familiares, pero con aspectos trillados y sin muchas novedades.

Ejemplo de lo antes dicho, fue la introducción de la variedad Tocúmen en la producción 
maicera. Los resultados fueron limitados, ya que permanecieron problemas como las plagas y las condiciones ambientales adversas. Las recomendaciones fundamentales del cambio técnico, al menos eran aplicables a los cultivos de postrera (había mayor acceso al crédito y seguros de cosechas), ya que tuvieron mejores condiciones que la de invierno, para facilitar un cultivo exitoso. Posterior, también se intento por medio de cruces entre híbridos blancos, con variedades criollas como el Maiceno, para obtener un mayor vigor. El combinado de variedades, pudo abrir nuevas posibilidades en momentos de crisis, empero esto no fue así, porque se necesitaba de un reforzamiento del gobierno y este careció de una estrategia de desarrollo. Entre 19811982 se hizo más evidente el encarecimiento de los insumos, esto se reflejo en la carestía de los fertilizantes, insecticidas y herbicidas, cuyo valor se incrementó en un 500 \%, por la una inflación superior al $30 \%$, sin duda un momento muy difícil para el agro costarricense.

En la administración de Luis Alberto Monge (1982-1986) se continuó con la investigación genética, por medio de los préstamos acostumbrados de la AID. También se tuvo como un fin primordial, el desarrollar estudios sobre el suelo, experimentar con nuevas variedades adaptables a la zona y avanzar en el cambio técnico. A pesar de esto, dicha administración redefinió el modelo de desarrollo económico, por lo tanto empezó a regir una producción basada en la importación de granos, incentivó la eficiencia productiva y la racionalización del sector público. Por otro lado, se tendió al debilitamiento del CNP, institución fundamental en la transferencia de semillas y el mejoramiento de las cosechas, por lo tanto, a partir de esta década se emprendió un descenso continuo de los sistemas de producción agraria en granos básicos. En el cantón se mantuvo con mayor intensidad el cultivo de arroz, mientras que el maíz decayó porque era cultivado con mayor fuerza por los pequeños y medianos productores. Contrario a su programa 
"Volvamos a la Tierra", la agricultura tuvo una disminución importante.

Otros problemas en lo interno del cantón, fueron una excesiva utilización de los terrenos o en condición de desmonte, la aplicación indebida de los abonos o agroquímicos, la deficiente utilización de maquinarias para preparar el suelo, los estragos realizados por la rata de campo y la utilización de terrenos no aptos por las sequías o lavados del suelo, ya que la década del ochenta las aridez fue el problema central, por el déficit de precipitaciones. ${ }^{13}$ (Esto se puede constatar en el cuadro No 2, sobre el uso de agroquímicos en Guanacaste)

Ante la crisis unas de la medida que se aplicaron fue el desvió de los cauces de los ríos o bien, por medio de la construcción de pozos profundos, para tratar de asegurar la continuidad de la explotación agrícola durante las sequía y así desarrollar cultivos con crecimiento-producción adecuado, controlar más fácilmente las enfermedades, porque el suministro de agua se convirtió en una fuente indispensable para la producción.

Desde 1950 había persistido la preocupación por el control de las inundaciones y sequías en la zona de Guanacaste. En la década de 1980 de grandes sequías, los técnicos del MAG, en conjunto con la organización estadounidense Sea Bees implementaron un estudio y construcción de posos profundos en las comunidades con producción agrícola y ganadera, incluyendo las de la zona en estudio. A pesar del avance en esta materia, los agricultores una vez más manifestaron algún recelo al cambio por la insuficiencia económica para el pago de electricidad de las bombas

13 En ese año el maíz que se sembraba en el mes de mayo (con el inicio de las lluvias), fue fuertemente afectado en la etapa de floración, limitando el desarrollo de la planta y la cosecha, asegurando apenas la recuperación parcial de la inversión, ya que el maíz no contaban con seguro de cosechas. Los graves problemas del arroz no distaban mucho de los del maíz, ya que la mala hierba perjudicó el rendimiento que se vio disminuido en 50 \%, porque los surcos se secaban por completo, por la perdida de humedad y la carencia de lluvias, Ídem. 
eléctricas. ${ }^{14}$ En las comunidades de Chircó y San Pedro, los grandes productores erigían embalses para estancar el agua por las sequías. Un agricultor de Lagunilla que trabajó en la Arrocera La Gilda cuenta “...habian embalses, para estancar el agua para cuando se daba la sequía, tenían sistemas de terrazas para regar por partes (...) tenían como un estero...o también sacaban agua de pozos que trabajaban con bombas. ${ }^{15}$

Ante las adversidades de la agricultura de granos básicos, la administración mantuvo un nivel de solvencia ante los problemas, ya que se activaron las ayudas económicas ausentes en la administración Carazo. En 1985 el Gobierno firmó el primer Programa de Ajuste Estructural, además se impulsó la siembra de sorgo y soya a tal punto, que en la zona en estudio los agricultores se inclinaron momentáneamente por ese tipo de producción. Las medidas inmediatas del gobierno, evitaron en gran medida las reacciones sociales. La iniciativa de mercado externo la continuó Oscar Arias (1986-1990). Esta iniciativa se puedo contemplar dentro de la diversificación productiva, la cual contemplaba zonas agrícolas la cuales exportarían la producción al exterior. Mediante el llamado Plan de Desarrollo.

La meta de esta administración, era la estabilización de la producción del país, por medio del funcionamiento de la empresa privada o por la importación de ciertos productos. Sin embargo, esa inserción de los empresarios, más allá de la estabilización, concretó una desestabilización aún mayor de los programas de crédito y de extensión agrícola, ya que pronto los agricultores se tenían que regir por medio de dos aspectos básicos: eficiencia y competitividad. Paradójicamente, en 1987 esta administración firmó otro Programa de Ajuste Estructura (PAE II). Al parecer de este 14 Conversación telefónica con Godofredo Gutiérrez. Desamparados, (San José). 9-112007.

15 Ídem. 
dinero se destinó muy poco para solventar los problemas de los agricultores de granos básicos, porque a diferencia de los años anteriores, era evidente el ausente Estado paternalista, que en cambio, se había tornado al neoliberalismo. En el caso particular de los agricultores de Santa Cruz, el gobierno no contempló que ante un panorama tan diferenciado entre los productores y el acceso a insumos, los agricultores tuvieron que competir con empresarios fuertes en la zona de Liberia, tras la puesta en marcha del Sistema de Riego de Moracia.

En 1988 fue uno de los últimos intentos de los pequeños y medianos agricultores por mantener el status quo, ya que tomaron de manera simbólica las agencias del sector agropecuario (MAG, Banco Nacional, IDA y Municipalidad) y presentaron un pliego de peticiones con las necesidades específicas. Tras los incidentes, los agricultores fueron recibidos por el presidente de la república Oscar Arias, sin embargo, las promesas de recomposición de la agricultura nunca se hicieron realidad y por el contrario, las acciones efectivas se destinaron al sector privado. El riesgo que representaba la producción agrícola, no fue viable, por lo tanto, se dejó la tradición productiva por los trabajos profesionales de sus hijos, o bien otros siguieron en una agricultura idílica, sin generarles ganancias.

\section{Redes de conocimiento, en la modernización de la agricultura de granos básicos en Santa Cruz, 1950-1990}

Después de explicar la evolución y los cambios experimentados en los sistemas de producción de granos básicos en Santa Cruz entre 1950-1990, es necesario indagar las formas de transferencia de información desarrollados en la agricultura. La transferencia provino de dos esferas: del conocimiento técnico formal y del informal. Las redes de conocimiento formal fueron promovidas 
por el Estado. Entre 1950 y 1970 estas estuvieron destinadas a todos los agricultores, pero a partir de 1970 la asesoría se reservó a los pequeños y medianos productores. Por otra parte, el conocimiento informal, bajo la difusión oral jugó un papel determinante, ya que por medio de la sociabilidad campesina desplegó el proceso de conocimiento. Ambas esferas a la postre generaron cadenas de información que significaron formas de generación, integración y distribución del conocimiento en el ámbito local. Si bien es cierto, los círculos académicos tuvieron una gran presencia en el cambio técnico por medio de las instituciones creadas por el Estado, no es de menospreciar el papel de los agricultores que fungieron como receptores y a la vez difusores de ese conocimiento entre sus similares.

La difusión agrícola, no era una novedad. Anterior al periodo de estudio (1950), la agricultura funcionaba gracias a una transmisión de tipo intergeneracional que aseguraba el traspaso de procedimientos en la agricultura tradicional. Los productores de la zona estudiada, tenían un acervo de conocimientos en el cultivo del maíz por influencia de la cultura indígena mesoamericana, que precedió al arroz posteriormente, introducido y desarrollado con el apoyo en las llamadas redes de transferencia informal adquiridas desde la colonia.

Por lo tanto, las prácticas tradicionales en la agricultura, eran sinónimo de enlaces de información entre diferentes generaciones de agricultores, ya que los individuos heredaban un conglomerado de patrones culturales, asociados a los oficios agrícolas. Estas práctica culturales impedían el cambio de manera inmediata, ya que era una arraigada tradición, que se traducían en "señales", técnicas de cultivos e instrumentos sencillos (espeque, machete, macana y churuco), que interferían directamente en los cultivos. Con posteridad a 1950, estos métodos de transferencia informal 
siguieron vigentes. De tal manera, que los nuevos insumos y maquinarias, se difundieron en estas mismas redes familiares y vecinales, así como la transmisión que se dio desde los grandes productores hacia los medianos y pequeños. En este proceso, se presentó tanto un acoplamiento y una fricción, entre los tres tipos de productores y los funcionarios del gobierno, reflejados en la desconfianza tanto a los sistemas de producción tradicional o moderna.

Entre 1950-1965, se empezó a realizar una especie de experimentación campesina, con las innovaciones en la agricultura Este método sin embargo, suscitaba la desconfianza y reticencia de los agricultores al cambio técnico, ya que para ellos, los sistemas de cultivo de granos, funcionaban satisfactoriamente para fines de autoconsumo. Los resultados de la experimentación se divulgaban por medio de las redes de información entre los agricultores, dándole soporte a la transferencia del cambio técnico generada por entidades estatales, que incorporaban el paquete tecnológico para el éxito de las siembras.

En general, el sistema de redes de información en la esfera informal funcionó de diferentes formas, 1) trabajando como peones en las propiedades de los grandes productores $\left.{ }^{16}, 2\right)$ mediante el dialogo con agricultores cercanos (vecinales y familia), 3) por razón de préstamo o venta de alguna innovación técnica y 4) la dotación de insumos, dinero y mecanismos de mercado implementados por la arrocera La Gilda (ubicada en la comunidad de San Pedro). Estas redes, funcionaban como sub-redes, porque fueron grupitos internos a las redes de una comunidad, ya que tenían relaciones más fuertes y un dialogó frecuente entre los vecinos.

16 El gran productor ponían en práctica las indicaciones de las instituciones estatales o bien, procedían por iniciativa propia. Está claro que, en este intercambio vecinal o laboral, también se incorporaron componentes ideológicos, ya que el pensamiento de progreso económico a través del cambio técnico, se transfirió a los peones de fincas. 
Si bien es cierto, las redes de transferencia informal jugaron un papel preponderante en la transferencia de la información, las redes de difusión formal fueron otra de las garantes en este aspecto. Desde 1950, paralelamente a la introducción del paquete tecnológico en Santa Cruz, funcionaron redes de conocimiento formales por parte del Estado. El CNP y STICA, fueron los principales introductores del cambio, a partir del asesoramiento técnico- científico. Estos contenidos partían de la idea de que una alianza estratégica entre los ingenieros agrónomos y los agricultores, permitiría optimizar los recursos para lograr el desarrollo productivo, procurado por el Estado Benefactor.

Los medios difusores fueron: las inspecciones (que entraron en funcionamiento en los sesentas), la extensión agrícola (por medio de la apertura del STICA en Santa Cruz en 1968), las parcelas demostrativas (para explicar las innovaciones en el campo) ${ }^{17}$ y las publicaciones (hojas, divulgativas, hojas sueltas, plegables, boletines técnicas, cuña en la radio y anuncios en televisión), que nacieron por la necesidad de divulgar las acciones investigativas en los sistemas de producción de granos básicos. ${ }^{18}$

Con la apertura del MAG (en 1970), se dio prioridad a los pequeños y medianos productores. La transferencia tenía una base de crédito supervisado, ofrecido por las entidades bancarias y el CNP, para lograr una mayor capacidad productiva. De esta manera, los técnicos cumplían con la misión de garantizar la recuperación del capital invertido por el Estado, tanto en créditos, 17 Rosales, Oscar. Informe de actividades del mes de Agosto de 1979 (inédito). Santa Cruz. MAG. 1979, sp.

18 Las temáticas que se divulgaban iban desde cómo aplicar el nuevo sistema de producción moderno, hasta el anuncio de la dotación gratuita de insumos para la producción. 
como en seguros de cosechas. Los diferentes medios difusores llegaron a múltiples sectores de la población, desde el punto de vista de la escolaridad y el nivel adquisitivo.

En 1979, el MAG puso en funcionamiento un nuevo programa de extensión llamado Clubes 4-S, esto en medio de la crisis. Con este se pretendía sustituir los cultivos de granos básicos, por una producción de hortalizas. A pesar de la política de diversificación agrícola, también se conservaron los granos, para hacerle frente a la crisis. El programa funcionó, mediante una red de informantes, donde ellos mismos fungían como coordinadores de proyectos con huertas caseras, escolares y familiares. Sin duda, este programa quería aprovechar las redes de información informales, e integrarlas a la transferencia formal. Otro programa que se puso en funcionamiento en esa década, fue el Programa de Asignaciones Familiares para la dotación de insumos, mayoritariamente gratis, por lo que se dio una dependencia de los agricultores a las instituciones estatales.

En la década de 1980, el seguimiento a los agricultores se realizaba de manera individual, para que fuera efectiva de cara a la situación y características particulares de cada agricultor. Sin embargo, es interesante como en plena crisis, los programas de difusión del conocimiento se dirigían a corregir los problemas por el uso incorrecto del suelo o por las prácticas culturales "indebidas", lo que deja entrever que el paquete tecnológico no había sido integrado en la totalidad por los agricultores. En la década del noventa, la extensión se orientó al estímulo de las organizaciones de productores o asociaciones para una progresiva capacitación y transferencia tecnológica, así como al mayor acceso a los servicios agrícolas. La estrategia (en investigación y extensión) consistía en equipos regionales, los cuales trabajaban en función de las necesidades 
del productor, para que lograra desarrollar mayores ingresos por la tecnificación. En este punto es evidente que la asistencia técnica dejó de ser de manera personalizada, por lo que pudo tener algunas implicaciones en la producción. El problema en la zona, es que no sobrevivieron muchos agricultores, pues la mayoría se dedicaron a otras actividades, ante la insuficiencia económica y desestructuración de la agricultura de granos básicos por parte del gobierno. ${ }^{19}$

Es interesante como dentro de la dinámica de la modernización agrícola, se dieron roces y choques culturales entre los agricultores y los ingenieros agrónomos. Por un lado, los extensionistas sentían una gran frustración, ya que los agricultores se negaban a implementar las constantes recomendaciones acerca del cambio técnico en granos básicos y los nuevos productos (muchas veces patrones copiados a diseños foráneos, sin darle la posibilidad de escogencia a los agriculturas). Mientras que los agricultores consideraban innecesarias algunas introducciones, como por ejemplo, las semillas híbridas, a cambio de las criollas. Las visiones absolutistas de ambos sectores, es parte del mundo diverso de una agricultura de cambio. Desde un principio, la desconfianza de los agricultores por las nuevas técnicas y la introducción del oneroso paquete tecnológico, eran símbolos de incomodidad y una señal de obstinación de ambos sectores, que de alguna manera fue superada por la necesidad de los agricultores tras el desgaste de la tierra y por lo programas de insumos gratis, que en el largo plazo generó una gran dependencia.

\section{Reflexiones finales}

Las políticas del Estado Benefactor, promovieron una base organizativa desde el punto de vista institucional para el desarrolló de la agricultura moderna, acorde a la corriente mundial de posguerra. Para ello se debía mejorar la condición de los agricultores en las zonas rurales,

19 Informes de Extensión Agrícola del MAG, (inédito), Santa Cruz, MAG. 1979, sp. 
sin embargo, estos manifestaron una fuerte dependencia al sistema de producción tradicional. Desde finales de la década del sesenta se evidenció la dependencia de los productores al cambio para incursionar en el mercado nacional. En ese proceso de acoplamiento, la agricultura se mantuvo entre la tradición y el cambio, aunque posterior a 1970 los agricultores se integraron a buena parte de la innovaciones, ante la pérdida de fertilidad del suelo, variaciones climáticas, plagas recurrentes, la incertidumbre ante la crisis mundial y las austeras políticas proteccionistas en este sector.

Bajo tal contexto, los sectores poderosos que incursionaron en la política con una lógica neoliberal (1986-1990), ignoraron los problemas de los productores de granos básicos y desarticulando el conglomerado institucional, dejando en solitario instituciones como el MAG, que le ha sido difícil atender el sector agrario A la postre, el estudio puede explicar a grandes rasgos, la modernización agrícola en las zonas rurales del país, por lo tanto puede llegar a ser comparado con los resultados de otras indagaciones, en regiones que también contaron con la influencia de estos proyectos de modernización agrícola.

Las redes de transferencia formal e informal, jugaron un papel preponderante en la incorporación del cambio técnico al sector agrícola. A partir de 1950, se impulsó el cambio técnico por medio de diferentes instituciones (STICA, CNP, MAG) y a la vez estas transfirieron la información mediante diversos mecanismos (dotación, extensión, asistencia técnica, parcelas demostrativas y material propagandístico, como folletos, hojas divulgativas, entre otros) y aprovechando las redes de información informales, donde se daban a conocer los resultados y adelantos a sus amigos, vecinos, familiares y peones trabajadores. Sin duda, es interesante como las disparidades 
entre los agricultores (pequeños, medianos y grandes) fueron aprovechados para apropiarse y difundirse el cambio técnico.

Ambos sectores, formales e informales, discreparon por la integración de técnicas modernas o tradicionales. Por la falta de compresión mutua, apertura y dialogo entre los sectores involucrados, ya que cada sector partió de la perspectiva unilateral. Dicha inconformidad, se añadió como otro inconveniente para desarrollo de la agricultura de granos básicos. Aunque muchas veces este paralelismo, indujo a la integración de aspectos tradicionales y modernos, dando como resultado una complementariedad en la agrícola.

Para reconstruir el proceso fue indispensable la utilización de fuentes orales, documentos inéditos del MAG en Santa Cruz, censos agropecuarios, periódicos y fuentes secundarias. Por lo tanto, se logró triangular la información para lograr la explicación y análisis del proceso de modernización agrícola. Si bien es cierto, no se tomaron en cuenta otras actividades productivas, como la ganadería y otros cultivos, así como las demás zonas productivas del cantón. El vacío de información deja espacio a indagaciones de manera comparativa, no sólo hacia lo interno en Santa Cruz, sino con otras zonas del país y Centroamérica.

Analizar esta dinámica de cambio es interesante, ya que se reconstruye un proceso de desarrollo. Pero más interesantes aún, es resaltar el lado humano de los procesos productivos, ya que más que indicadores numéricos y explicaciones físico-biológicas, que no se aplican en esta investigación, fueron dinámicas sociales que desde lo rural participaron en un contexto nacional. Es una realidad donde el agricultor se ha enfrentado a dinámicas socio-económicos diferentes, 


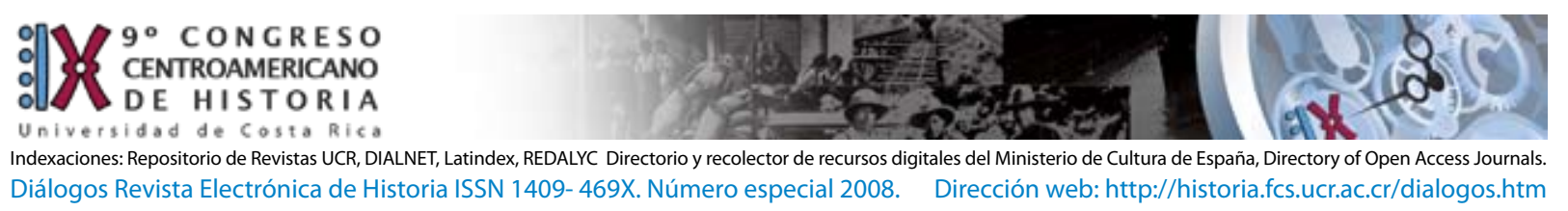

que lo orientaron a adaptarse lentamente a un sistema de producción totalmente moderna y ajena a su mundo rural. Inconcluso permanece la comparación si las lógicas de los agricultores tienen similitudes o diferencias con respecto a una esfera de nivel mayor, como la escala macro del caso centroamericano y comprender de esta forma, el papel de los agricultores en nuestras sociedades.

Es inevitable pensar en las paradojas que tiene el sector agrícola de los granos básicos en nuestra actualidad, ante en la crisis alimentaría que está desarrollando. Por un lado, estamos consiente que las implicaciones son el resultado de la desestructuración del sector agrario en décadas pasadas y lo contradictorio es que según las palabras del director del MAG en Santa Cruz una de las salidas sea volver a cultivar las variedades criollas, que por su capacidad natural se adaptan sin mayores problemas a las condiciones ambientales y socio-económicas de los agricultores. 


\section{Fuentes}

\section{Censos}

Dirección General de Estadística y Censo. Censo Agropecuario 1973. San José. Ministerio de Economía., Industria y Comercio. 1974.

Dirección General de Estadística y Censo. Censo Agropecuario 1984. San José. Ministerio de Economía., Industria y Comercio. 1985.

\section{Periódicos}

El Agrario Nacional, 7 de octubre de 1950

El Agrario Nacional, 7 de octubre de 1950

Repertorio Agrícola, 22 de julio de 1950

\section{Informes del MAG}

MAG, Informe de granos básicos, 1978, Santa Cruz, 1978.

- "Pruebas de densidad de siembra y niveles de fertilización del maíz en Santa Cruz

de Guanacaste”. En: Boletín sobre investigaciones agrícolas. Vol. 2 San José. Editado en el Departamento de Comunicaciones Agrícolas e Información Técnica del MAG. Vol. 2, 1975 , Informe narrativo del Proyecto Arroz (inédito), 1984. Santa Cruz. 1984

Ministerio de Agricultura y Ganadería. "Pruebas de densidad de siembra y niveles de fertilización del maíz en Santa Cruz de Guanacaste”. En: Boletín sobre investigaciones agrícolas. Vol. 2 San José. Editado en el Departamento de Comunicaciones Agrícolas e Información Técnica del MAG. Vol. 2, 1975. , Informe narrativo del Proyecto Arroz (inédito), 1984. Santa Cruz. 1984. 
, Análisis del sector agropecuario de la Región Chorotega respecto a la sequía que afecta la cosecha de granos básicos de la región, (inédito), Liberia, 1982.

_, Informe del MAG del distrito de 27 de Abril, (inédito).1984. Santa Cruz. , Informe de los principales agroquímicos usados en la producción hortícola en Costa Rica, San José, Dirección general de mercadeo. 1979.

$\longrightarrow$ Unidades de juventudes rurales -clubes

4-S y ama de Casa. Grupos asociados de producción rentable algunos elementos generales para su planificación, 1979. , Informe del distrito de 27 de Abril, 1984 (inédito) Santa Cruz. MAG. 1984 , Uso de insecticidas en el combarte de Liriomyza SP. San José. 1990

Suárez, Carlos. Hoja Divulgativa, Fertilización del cultivo de maíz. Liberia. MAG. 1983.

\section{Entrevistas}

Entrevista con Alejandro Gutiérrez, San Pedro, (Santa Cruz), 26-19-2007.

Entrevista con Demetrio Arrieta, Lagunilla, (Santa Cruz), 29-9-2007.

Entrevista con Enrique Leal, Las Delicias, (Santa Cruz), 17-9-2007.

Entrevista con Godofredo Gutiérrez. (Santa Cruz), 17-9-2007.

Entrevista con José Maria Gutiérrez. Las Delicias de 27 de Abril, (Santa Cruz), 1-10-2007.

Entrevista con Luis Angulo, Las Delicias de 27 de Abril, (Santa Cruz), 17-9-2007.

Conversación telefónica con Godofredo Gutiérrez. Desamparados, (San José). 9-11-2007

\section{Secundarias}

Alfaro, Javier. Maíz, San José, CNP, Departamento agro-técnico del maíz, 1981, p, 12-17. 
Armijo, Freddy y Rosales Jonny. Consejo nacional de de investigaciones científicas y técnicas. Transferencia privada de tecnología agrícola en Costa Rica el caso de la semilla en café, caña de azúcar, arroz y maíz. San José. Ministerio de agricultura. 1983

Arnault, Villaret. El enfoque sistemático aplicado al análisis del medio agrícola. Definición adaptada de Dufumier. 1985

Calatayud, Salvador, Pan-Montojo, Juan y Pujol, Joseph. Innovación y cambio técnico en la agricultura. Revista Historia Agraria. No. 27. España. Editorial. Agosto, 2002

Dufumier, Marc. Historia agraria para los agrónomos. Revista de Historia. No. 47.Heredia, Costa Rica. Editorial de la Universidad Nacional. Enero-junio, 2003

Edelman, Marc La lógica del latifundio. San José. Editorial de la Universidad de Costa Rica. 1998

Campesinos contra la globalización, movimientos sociales rurales en Costa

Rica. San José, 2005

Fuentes, Rafael, Informe anual de actividades 1979. Santa Cruz, MAG, 1979

García, Teresa; Guerrero, Pilar; Quirós, Carlos; Roa, José; Beltrán, Jorge. Organización de agricultores que participan en la investigación agrícola y en el desarrollo de tecnologías. México. Fundación Rockefeller. En: Red, Gestión de Recursos Naturales. N 10, enero- marzo de 1998 Guzmán, Danilo. Estudio detallado del suelo y clasificación por capacidad del suelo y apta para riego de las tierras de la finca experimental e Santa Cruz. Liberia. Tesis de agronomía de la UCR, 1987

Inarte, Eduardo José. Articulación entre generación y transferencia de tecnológica agropecuaria. Elementos sobre la elaboración sobre un marco de Referencia para la cooperación del IICA en transferencia de Tecnología. San José, Costa Rica. Serie Publicaciones Miscelaneas. 1990 
León, Jorge; Aguilar, Justo; Barboza, Carlos. Un análisis del desarrollo científico tecnológico del sector agropecuario de Costa Rica, San José Consejo Nacional de investigaciones científicas y técnicas. 1982

Malespín, Irving, Informe anual, 1979 (inédito). Santa Cruz, Guanacaste. MAG. 1979

Masís, Germán. La agricultura campesina en Costa Rica: alternativa y desafíos en la transformación productiva del agro. San José. IDEAS, 1994

Morales, Cesar. Sistemas de innovación agrícola en América Latina y el Caribe. Heredia. Gestión Tecnológica y Desarrollo Rural. EUNA. 1999

Piñero, Martín. Transición tecnológica y diferenciación social en la agricultura latinoamericana.

San José. Instituto Interamericano de Cooperación para la agricultura. 1986

Ramírez, Pedro. Prácticas efectuadas en una finca de ganado de carne Santa Cruz Guanacaste. Facultad de Agronomía de la UCR. 1976.

Román, Isabel. ¿Conciliación o conflicto?, Luchas campesinas y democracia en Costa Rica. San José, Editorial Porvenir, 1994

Rosales, Oscar. Informe de actividades del mes de Agosto de 1979 (inédito). Santa Cruz. MAG. 1979

Salazar, Norma. Fertilidad de suelo de la Finca Experimental de Santa Cruz. Tesis de Licenciatura de la UCR, 1991

Samper, Mario. Redes sociales y comunicación entre experimentadores campesinos en Puriscal. Costa Rica. UNA

Sfez, Paul. Entre la tradición y el cambio: Evolución Tecnológica de la Caficultora Costarricense. San José. SEE S.A. 2000 . Proyecto: modernización y crisis de la caficultora centroamericana: evolución 


\section{OI $9^{\circ}$ CONGRESO

Indexaciones: Repositorio de Revistas UCR, DIALNET, Latindex, REDALYC Directorio y recolector de recursos digitales del Ministerio de Cultura de España, Directory of Open Access Journals. Diálogos Revista Electrónica de Historia ISSN 1409-469X. Número especial 2008. Dirección web: http://historia.fcs.ucr.ac.cr/dialogos.htm

reciente y perspectivas. Instituto Panamericano de Geografía e Historia y Universidad Nacional Facultada Ciencias Sociales. Escuela de Historia. 1996

Vargas, Alberto. El arroz en Costa Rica. San José. MAG, Dirección de investigaciones Agrícolas, 1971

Vermeer, René. El cambio en la agricultura, el caso de los granos básicos durante la administración Arias. San José. CENAP. 1990 


\section{ON $9^{\circ}$ CONGRESO \\ - $\$$ CENTROAMERICANO

Indexaciones: Repositorio de Revistas UCR, DIALNET, Latindex, REDALYC Directorio y recolector de recursos digitales del Ministerio de Cultura de España, Directory of Open Access Journals.

Diálogos Revista Electrónica de Historia ISSN 1409-469X. Número especial 2008. Dirección web: http://historia.fcs.ucr.ac.cr/dialogos.htm

\section{ANEXOS}

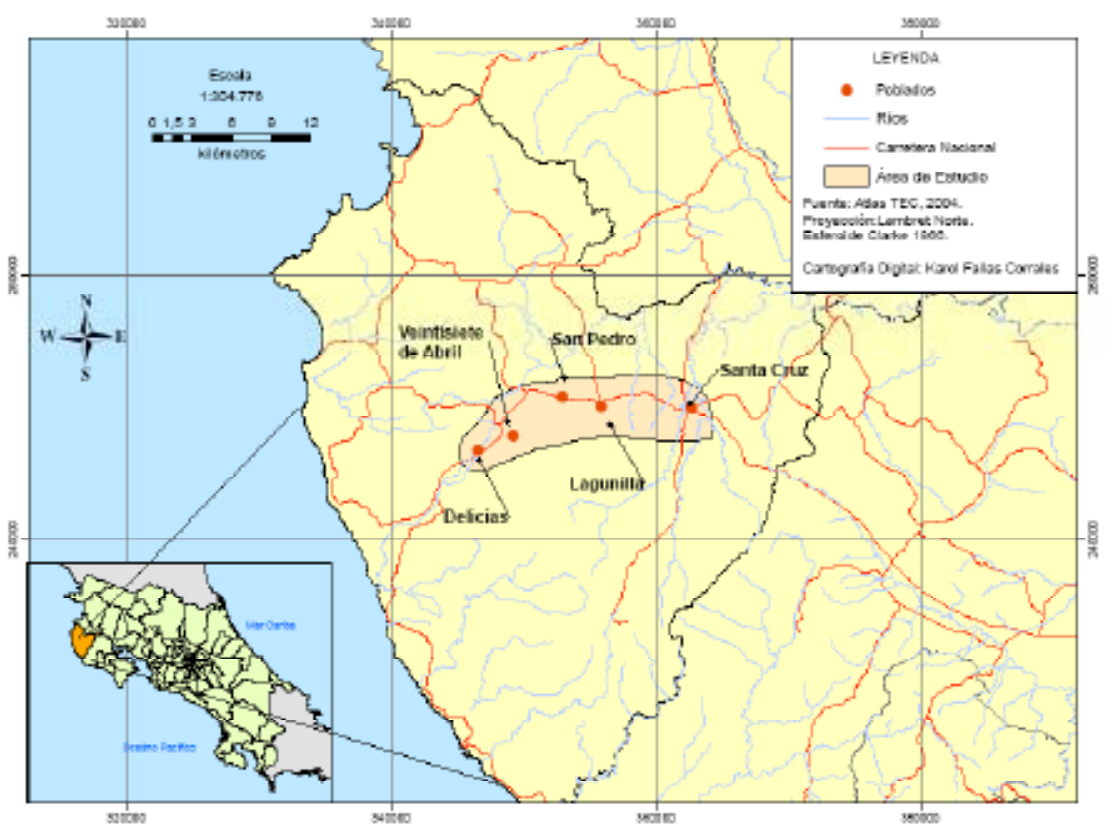

Anexo No 1. Mapa de la región estudiada 
Indexaciones: Repositorio de Revistas UCR, DIALNET, Latindex, REDALYC Directorio y recolector de recursos digitales del Ministerio de Cultura de España, Directory of Open Access Journals. Diálogos Revista Electrónica de Historia ISSN 1409- 469X. Número especial 2008. Dirección web: http://historia.fcs.ucr.ac.cr/dialogos.htm

\section{Cuadro $\mathbf{N}^{\circ} \mathbf{1}$}

Uso de agroquímicos en Guanacaste, 1984

\begin{tabular}{ll}
\hline Innovación Química & Aplicación en fincas \\
\hline Pesticidas & 336 \\
Herbecidas & 547,8 \\
Otros tipo de insecticidas & 379,5 \\
Abonos Químicos & 927,3 \\
Maquinaria & 822 \\
\hline
\end{tabular}

Fuente. Censo Agropecuario de 1984.Elaboración Propia.

\section{Cuadro $\mathbf{N}^{\circ} 2$}

Tenencia de maquinaria en el distrito de 27 de Abril, 1973

\begin{tabular}{ccc}
\hline Maquinaria & Cantidad & Fincas \\
\hline Tractor & 30 & 20 \\
Arado de tiro & 8 & 6 \\
Arado de tractor & 8 & 13 \\
Rastras & 22 & 15 \\
Sembradoras & 6 & 6 \\
Cosechadoras & 1 & 1
\end{tabular}

Fuente: Censo Agropecuario 1973. Elaboración Propia, p, 183. 